\title{
Por uma clínica de(s) território no contexto do SUS
}

\author{
Mariane Marques Santos Amaral, (D) ${ }^{\star}$ Liliana da Escóssia \\ Universidade Federal de Sergipe, Sergipe, SE, Brasil
}

\begin{abstract}
Resumo
O texto analisa caminhos possíveis para uma prática clínica no/de território, no contexto do Sistema Único de Saúde (SUS). A trajetória de trabalho como psicóloga de uma de suas autoras, de 2007 a 2015, em diferentes unidades do SUS, serviu de campo para uma cartografia, entendida como método de pesquisa-intervenção. Nesse contexto, acompanhamos processos de constituição de diferentes modos de pensar e de fazer clinica, a partir de registros de cenas do cotidiano de trabalho. Estas, uma vez revisitadas, compuseram uma narrativa cartográfica de experiências. A pesquisa foi pautada por algumas noções: de clínica, como catalisadora de encontros produtores de passagens e desvios, operada no "entre fronteiras"; de saúde, como processo de produção, realizado por meio de agenciamentos; de território, como espaço de vida e processo. Com a pesquisa, afirmamos ser possível construir uma prática clínica de "corpos agenciadores" que se faz "no" território de vida das pessoas, e "de" território, ao incorporar seus elementos e acompanhar o movimento de (des) construção de paisagens subjetivas, num plano coletivo e movente. Ao engajar-se com o plano de constituição da vida, onde ela acontece, esta clínica se faz política, posiciona-se frente aos regimes de sociabilidade postos, fortalecendo o que há de público no SUS.
\end{abstract}

Palavras-chave: prática clínica; saúde; território; SUS; narrativa cartográfica.

\section{For a clinic of territory in the context of SUS}

\begin{abstract}
This paper examines possible paths for a clinical practice in/of territory, in the context of the Sistema Unico de Saúde (SUS), the Brazilian unified health system. The work trajectory as a psychologist of one of its authors, from 2007 to 2015, in different units of SUS served as a field to a cartography, which is used as a method of research-intervention. In this context, we follow the constitution processes of different ways of thinking and doing clinical work, based on records of everyday work scenes. These, once revisited, composed a cartographic narrative of experiences. The research was guided by some notions: of clinical, as a catalyst for meetings that produces passages and deviations, operated in the "between borders"; of health, as a production process, carried out through assemblages; of territory, as a space of life and process. With this research, we claim that it is possible to build a clinical practice of "assembling bodies" that takes place "in" the people's life territory, and "of" territory, when it incorporates its elements and when it accompanies the movement of (de) construction of subjective landscapes, on a collective and moving plane. By engaging with the plan of constitution of life, where it actually takes place, this clinical work becomes political, positions itself against the sociability regimes put in place, strengthening the public aspects of SUS.
\end{abstract}

Keywords: clinical practice; health; territory; SUS; cartographic narrative.

\section{Introdução}

Esse texto parte de experiências afetivo-profissionais vivenciadas no contexto do trabalho do SUS, como psicóloga, ao longo dos últimos dez anos, por uma de suas autoras. Durante esse processo, muitos encontros e práticas foram possíveis, alguns intensificando ou expandindo a vida, outros dificultando ou impedindo seu movimento de criação. Inquietações, alegrias e incômodos nos levaram, inicialmente, a refletir sobre a relação entre estas experiências e um certo modo de fazer e pensar a clínica no SUS. Posteriormente essas reflexões se transformaram em problemas de pesquisa no contexto de um mestrado em Psicologia Social.

A discussão sobre a clínica no contexto do SUS tem sido abordada por diversos autores, a partir de conceitos como Clínica Ampliada e Clínica Transdisciplinar. Para a Política Nacional de Humanização (PNH), "no plano da saúde coletiva, ampliar e compartilhar a clínica é construir processos de saúde nas relações entre serviços e a

\footnotetext{
${ }^{\star}$ Endereço para correspondência: Universidade Federal de Sergipe, Centro de Educação de Ciências Humanas, Departamento de Psicologia. Cidade Universitária Prof. José Aloísio de Campos. Av. Marechal Rondon, s/n, Jardim Rosa Elze - Aracaju, SE - Brasil. CEP: 49015000.Emails: marianefj@yahoo.com.br, lilianaescossia@gmail.com

Os dados completos das autoras encontram-se ao final do artigo.
}

comunidade de forma conjunta, participativa, negociada" (BRASIL, 2009, p. 11), e para tal torna-se imprescindível a ampliação e o compartilhamento de saberes. Assim, a clínica ampliada "é uma clínica transdisciplinar, isto é, é a invenção de novas possibilidades de vida, de outros modos de existência, através do atravessamento de diferentes saberes e práticas" (IGNÁCIO, 2011, p. 30). O nosso trabalho mantém com estes conceitos uma estreita vinculação teoria, ética e política. A ênfase na questão do território e a afirmação de uma clínica de/no território resulta da análise das experiências-questões, daquilo que emerge como força decisiva na experimentação de uma certa trajetória clínica, aproximando o nosso trabalho de outros já realizados sobre a relação entre clínica e território no SUS (ALEXANDRE; ROMAGNOLI, 2017; IGNÁCIO, 2011; LIMA; YASUI, 2014).

Buscamos com nossa pesquisa percorrer caminhos possíveis para uma prática clínica no/de território, não só "psi", mas de "corpos agenciadores". Tomamos, para tanto, a noção de clínica como catalisadora de encontros produtores de passagens e desvios, capazes de tecerem modos de existência conectados com um território que é experimentado, imanente, vivo e pulsante. 
Com esse entendimento, forjamos o termo "corpos agenciadores" a partir do encontro das noções de corpo de Foucault (2001) e de agenciamento de Deleuze e Parnet (1998). Corpo pode ser entendido, a partir de Foucault (2001), como uma superfície de inscrição dos sujeitos que somos levados a nos tornar a partir das relações de saber/poder vivenciadas em uma determinada sociedade. O corpo seria, como explicam Machado, D., Vasconcelos e Melo (2012), uma espécie de montagem que se faz num plano de tensão entre formas de sujeição e forças de experimentação, por meio de agenciamentos. Agenciar, por sua vez, é articular provisoriamente subjetividades, coisas, regimes de signos, ações e paixões, com a criação de algo que não está nem em um nem no outro, mas entre os dois, em um plano coletivo e movente, espaço-tempo comum e impessoal. Comum "é o que é construído no encontro e não o que já existia de comum, na forma de traços de identidade, de classes ou gêneros. Dimensão espaço-temporal de correlação e coengendramento" (ESCÓSSIA, 2014, p. 92).

Como uma clínica de "corpos agenciadores" opera "no" território de vida das pessoas e se constitui, ao mesmo tempo, como uma prática "de" território, incorporando seus elementos? Como inventar práticas produtoras de saúde e habitar territórios existenciais, acompanhando sua (des)construção?

Nosso objetivo é discutir essas questões sem intenção de esgotá-las. Escrever tal como um experimentador, que, segundo Foucault (2010), escreve porque não sabe ainda exatamente o que pensar sobre algo que gostaria muito de pensar e está disposto, nesse processo, a se transformar, a rever pensamentos e práticas.

Escrevemos sobre clínica, saúde, corpo, território e SUS muito atentos ao fato de que as palavras nos enganam. Elas fazem-nos acreditar que as coisas existem por elas mesmas, quando na verdade, como aponta Veyne (1982), não passam de correlatos das práticas correspondentes, sendo necessário um olhar atento à naturalização de conceitos.

Feitas essas ressalvas, cabe-nos discutir os caminhos metodológicos que nos permitiram produzir algumas respostas para as perguntas acima propostas.

\section{Caminhos metodológicos}

Utilizamos a cartografia como método de pesquisa-intervenção. Trata-se de um método proposto por Deleuze e Guattari, como explica Kastrup (2008), para o estudo da dimensão processual da subjetividade e de seu processo de produção, cuja orientação do trabalho do pesquisador não se faz através de metas predefinidas, estas são traçadas no percurso da pesquisa, à medida que acompanhamos uma paisagem subjetiva sempre movente.

Segundo Passos e Barros (2009), este método de pesquisa articula-se a um modo de produção de conhecimento, cujo pressuposto inicial é de que a presença do pesquisador afeta a condução da pesquisa. Além disso, a orientação do trabalho do pesquisador não se faz através de regras predefinidas, nem de objetivos estabelecidos de forma definitiva, sendo as metas traçadas no caminhar, no percurso da pesquisa. Cartografar, nesse sentido, é acompanhar um processo, e não representar um objeto, negligenciando o fluxo processual no qual está sendo produzido.

Como acompanhar o fluxo processual no qual os "objetos" que estudamos - clínica, produção de saúde, SUS, território - vão se construindo? Na pesquisa realizada, o primeiro movimento, no sentido de acompanhar esse fluxo, se deu por meio da elaboração de cadernos de formação. Começamos a trabalhar no SUS em 2007, passando por diferentes equipamentos - Unidades de Saúde da Família (USF), Centros de Atenção Psicossocial (CAPS), Hospital Geral e Maternidade. Mantivemos o costume de registrar, em cadernos, o cotidiano de trabalho, como pautas de reuniões, dúvidas, falas e cenas que afetaram e fizeram pensar. Esses cadernos de registros do cotidiano das práticas de trabalho-formação-experimentação são denominados por Machado, D. (2011, p. 49) de cadernos de formação.

Com o ingresso no mestrado em 2013, iniciamos a confecção de um diário de campo, com registro regular de práticas de atenção à saúde no CAPS Liberdade, local onde uma das autoras deste texto trabalhava como psicóloga. Revisitamos os cadernos de formação e os diários de campo. Considerando o que havia sido escrito como uma paisagem, lançamos a atenção para o que mais nos afetava: as rugosidades e os relevos dessa paisagem de pesquisa. Nesse processo, algumas rugosidades foram transformadas em "experiências-questões". São narrativas que descrevem e analisam um problema, algo desconhecido e inesperado, que pede passagem, força pensar e nos permite questionar os limites do que pode ser entendido ou dito.

A narrativa de "experiências-questões" é um pouso que prova, experimenta, tensiona as forças de um território, assumindo o perigo que há nesse movimento de abertura ao desconhecido. Colada à experiência, como uma coisa só, está a questão. Ao questionarmos/problematizarmos um território, abrimos caminhos, realizamos travessias, vivenciamos a transformação do presente.

Diante da impossibilidade de trazer para este artigo as dez "experiências-questões" da dissertação, duas delas foram selecionadas a fim de que, a partir de sua discussão, possamos vislumbrar caminhos possíveis para uma prática clínica no/de território e de "corpos agenciadores", no contexto do SUS.

\section{Experiência-questão: jogando o corpo no mundo}

No dia 23/09/2013, uma colega e eu fomos avisadas de que teríamos um acolhimento inicial para fazer. Chamamos Alex, que segurava um saco enorme com seus pertences e estava acompanhado por um trabalhador do Centro de Referência Especializado de Assistência Social para População em Situação de Rua (Centro Pop).

Começou a contar sua história, disse que tinha 32 anos, era natural de Contagem-MG, tinha 15 irmãos, muitos envolvidos com tráfico de drogas, outros presos. Sua casa era um inferno, sentia-se mal lá e por isso decidiu "sair andando pelo mundo", palavras dele. Passou por algumas cidades, demorando mais tempo em umas do que em outras. Morou um tempo em São Paulo numa instituição religiosa, gerenciada por freiras. Como eram 
muitas regras, decidiu sair. Ficou em situação de rua e usava maconha e crack. A última cidade em que esteve por mais tempo foi Feira de Santana-BA, onde frequentava um CAPS. Falou várias vezes que tinha esquizofrenia, estava sem remédios e queria retomar o tratamento. Fiquei confusa, o que Alex queria do CAPS? Tratamento? Tratamento de que e para quê? Ele não parecia confuso, demonstrava que estava bastante seguro de sua decisão. Falava pelos cotovelos: tinham cidades que o empurravam para frente, outras não; possuía cinco CIDs, mas ninguém do "INPS" queria aposentá-lo; não tinha condições de trabalhar. No "albergue" (Casa de Passagem) em que estava, deram-lhe um prazo para ficar. Este poderia ser estendido, caso estivesse procurando um emprego, coisa que não pretendia fazer.

Alex estava orientado no tempo e no espaço, apresentava discurso coerente, humor eutímico, higiene preservada e uma porção de outras palavras bonitas que caracterizam uma pessoa dita "normal". Senti que a conversa estava ganhando tom de um desconfortável interrogatório, no qual Alex tentava nos convencer de que realmente precisava do CAPS. Com várias pulgas atrás da orelha, para que tivéssemos condições de conhecê-lo melhor, decidimos admiti-lo no serviço.

Por fim, perguntamos quais eram seus projetos de vida. Respondeu quase que imediatamente: "Quero descansar um pouco para continuar andando e enquanto estiver aqui vou fazer o tratamento". Aquele encontro me fez sentir coisas estranhas, difíceis de serem processadas naquele momento.

$\mathrm{Na}$ primeira reunião de equipe após o acolhimento de Alex, informei sobre o mais novo integrante do CAPS. Contei que Alex não tinha interesse em conviver com familiares, não aparentava ter um transtorno mental grave, conhecia muito bem os serviços tanto da Assistência Social como da Saúde e que, inclusive, tinha decidido vir a Aracaju porque ouviu dizer que as coisas aqui funcionavam.

Após alguns dias, o prazo de Alex na Casa de Passagem findou, e ele voltou a dormir na rua. Passou a chegar ao final da manhã para a atividade que começaria às $16 \mathrm{~h}$, falava que se sobrasse almoço iria querer. Procurava profissionais em turnos diferentes para solicitar mudanças em suas atividades no CAPS, já que, à medida que ia conversando com outros usuários, ia descobrindo outras possibilidades de estar naquele serviço.

Certa vez, uma das trabalhadoras da Casa de Passagem esteve no CAPS, solicitando avaliação da nossa equipe para um rapaz que a estava acompanhando. Alex, que na ocasião estava no pátio, viu a moça passar, rapidamente chamou uma assistente social do CAPS e solicitou que aproveitasse para perguntar-lhe se ele poderia voltar a dormir lá. Conversa vai, conversa vem, na mesma semana voltou a frequentar o "albergue".

Da mesma forma que se articulava dentro, fazia fora do CAPS. Frequentava aulas de yoga que aconteciam num centro espírita e conseguiu (não sei como) fazer a

Fractal, Rev. Psicol., v. 33 - n. 1, p. 31-40, 2021 carteirinha interestadual de passe-livre. Deixou de frequentar o Centro Pop porque conseguia, segundo ele, sabonete, gilete e pão de outras formas.

Quando voltei de férias, comentei com alguns colegas como tinha sido lindo conhecer o vale do Pati, na Chapada Diamantina-BA. Não percebi que Alex estava atrás de mim. Minutos depois, ele procurou uma colega e pediu que escrevesse no papel o nome do lugar onde eu fui, porque ele queria conhecer também. Depois de três meses, parece que o motorzinho que faz Alex conhecer o mundo voltou a funcionar: comentou com alguém que iria para Recife-PE.

O encontro com Alex amplia na equipe o desejo de trabalhar menos e viajar mais. Além disso, Alex, tal como na parresia, ${ }^{1}$ discutida por Foucault (2011), leva-nos a rir e a afrontar aquilo que supostamente defendemos. Narrando sua (nossas) experiência(s), ficamos de frente com o dilema ético de descobrir se a vida verdadeira não deveria ser uma outra vida. Uma vida que se coloca à prova da verdade, que experimenta, estica, rompe os limites de seu território e, por isso, é uma "vida outra" de transgressão e ruptura.

Esse questionamento sobre a vida verdadeira nos fez pensar se os conceitos de saúde/doença e intervenções que produzimos a partir da "internalização" desses conceitos também não poderiam ser outros. Andar incessantemente pelo mundo é sinônimo de transtorno mental? É doença? O que produzimos quando tomamos unicamente a doença e o seu conjunto de sintomas e sinais cientificamente preestabelecidos como critérios para criar práticas produtoras de saúde?

\section{Produção de saúde e corpos agenciadores}

Aquilo que entendemos comumente por saúde está relacionado com normas e modulações que estabelecem o modo como o ser humano deve se relacionar consigo mesmo e com o mundo. Assim, a saúde não é um objeto invariável, que independe da relação que temos com ele e da forma como o acessamos. O mesmo acontece em relação à noção de corpo, produzida ao longo da história através de múltiplos atravessamentos econômicos e políticos, influências de conhecimentos e práticas filosóficas, religiosas e científicas, sempre em transformação.

Desses atravessamentos, destacamos a influência do pensamento platônico e cartesiano, para uma determinada forma de habitar nosso corpo e o mundo. Para Platão, conforme explica Fuganti (2008), o mundo está dividido entre plano das essências - espécie de plano divino, das formas inteligíveis verdadeiras e imutáveis, alcançadas pelo pensamento - e plano das aparências - mutável, espécie de cópia do mundo das essências, atingido através da experiência sensível. Aqui, não se chega à verdade por

${ }^{1}$ Foucault (2011) explica a noção de "parresia" em curso ministrado no Collège de France (1983-1984), intitulado A coragem da verdade: o governo de si e dos outros II. Parresia vem do grego parrhêsia e significa coragem de dizer a verdade, falar livremente, dizer tudo, como prática de vida. Nas investigações sobre a cultura greco-romana do cuidado de si, Foucault (2011, p. 4) discorre sobre essa "modalidade do dizer-a-verdade", que se difere completamente dos "discursos que se dão e são recebidos como discursos verdadeiros", como é o caso da verdade na modernidade ocidental, fundamentada em um tipo específico de conhecimento. Foucault (2011, p. 4) buscou compreender "sob qual forma, no seu ato de dizer a verdade, o indivíduo se constitui ele mesmo e é constituído pelos outros como sujeito detentor de um discurso de verdades", entendendo a produção de verdade no ato pelo qual tal produção se manifesta. 
meio da experiência dos corpos no mundo. Essa é alcançada de forma transcendente, através de um movimento do pensamento, em direção a ideias eternas e verdadeiramente reais do plano das essências.

Essa dicotomia entre corpo e mundo volta a aparecer, muitos anos depois, na filosofia da representação de Descartes (1996). Por volta do século XVII, surge no Ocidente uma grande preocupação em tornar claras as bases seguras para a produção e avaliação do conhecimento verdadeiro. Diante dessa demanda, o pensamento cartesiano afirma a existência de duas totalidades. De um lado o mundo, já definido e pronto; de outro, o homem racional, que existe justamente por sua capacidade inata $\mathrm{e}$ natural de (re)apresentar, (re)conhecer a realidade através de uma interiorização do visível e do enunciável, que o conduz até a verdade.

Essa forma de pensar, marcada pela relação dicotômica entre sujeito e objeto do conhecimento, aliou-se às demandas do mercado capitalista em ascensão, contribuindo para que, principalmente a partir do século XVIII, tomássemos o corpo como corpo-privado-individual, descolado da realidade onde vive, sendo natural a definição de saúde como o contrário de doença. Isto porque a ideia "estou saudável porque não estou doente" parte do mesmo raciocínio dicotômico que separa corpo e mundo. Os termos em questão - saúde e doença - são considerados como já previamente definidos. Além disso, a existência de um pressupõe a ausência do outro. Se não há coexistência, não há um "entre", algo que se produza na relação entre saúde e doença e que inevitavelmente transforme aquilo que entendemos por cada um desses termos.

Não queremos tomar essa forma de entender o mundo como base para nossas práticas clínicas no SUS. É importante desnaturalizar as dicotomias e os termos que a constituem. Daí a ideia de uma clínica de "corpos agenciadores", e não de indivíduos detentores de uma subjetividade privatizada, de uma faculdade inata capaz de reconhecer o mundo.

Para Deleuze e Parnet (1998), os agenciamentos relacionam-se a dois planos. O primeiro, o plano das formas, diz respeito às figuras já estabilizadas, aos objetos que reconhecemos no mundo. Concerne ao desenvolvimento da harmonia das formas e à formação dos sujeitos. Essas formas são fruto de agenciamentos provisórios que se movimentam no plano de forças, caracterizado por ser imanente e coletivo, já que não remete a nenhum objeto e não pertence a nenhum sujeito.

Podemos pensar a produção de saúde se fazendo nesse processo, onde as formas seriam concepções de corpos saudáveis, conhecimentos científicos de profissões da área da saúde, imagens de corpos saudáveis propagadas pela mídia, leis, maneiras de consumir determinados produtos. As forças seriam o constante movimento de criação de novos contornos nos corpos (individuais, coletivos, biológicos, psicológicos), atravessando-os, esticando seus limites, inventando relações inimagináveis, produtoras de saúde por expandirem a vida, num movimento de biopotência, numa relação dionisíaca com o mundo.
Nesse sentido, fica difícil conceber saúde como uma essência que caracterizaria um estado de normalidade dos seres humanos, já que, para nós, ela se faz num constante processo de produção de "corpos agenciadores". Como diria Canguilhem (1978), a saúde se caracteriza pela sua normatividade, ou seja, pela sua abertura às modificações, sua capacidade de inventar novas normas e não se fixar em normas já estabelecidas. A doença é uma experiência de inovação positiva do ser vivo, e não apenas um fato diminutivo. Tal concepção marca um posicionamento político, ao negar a possibilidade de uma sociedade totalmente saudável e sem diferenças. Mesmo porque a ideia de uma saúde perfeita acabaria conformando uma nova patologia, já que implicaria a perda do exercício normativo. Ou, numa concepção nietzscheana, provocaria a perda da capacidade dos corpos de, a partir da experiência, interpretarem o mundo e afirmarem sua vontade de potência, lançando-se na aventura de sua autoprodução (NIETZSCHE, 2008).

Voltemos a Alex. Sentimos que parte dele um convite. Caso queiramos construir práticas produtoras de saúde, talvez nos caiba prestar menos atenção na definição e tratamento de um "CID", dando mais importância aos agenciamentos (im)possíveis de serem forjados, aos elementos que podem ser conectados. Trata-se de um desafio, já que, no contexto do SUS, surgem muitas amarras que dizem respeito à relação do Estado com as encomendas de um modo de produção capitalista. Contudo, justamente porque temos o SUS como pano de fundo, é possível potencializar a produção de tais agenciamentos. Isso porque sua dimensão pública pode fortalecer a construção de agenciamentos coletivos. Além disso, a afirmação da equidade, integralidade, universalidade, produção de autonomia e participação social - princípios do SUS que não estão dados e precisam constantemente ser problematizados - é capaz de colocar em movimento encontros produtores de saúde no sentido proposto por Canguilhem (1978) e Nietzsche (2008).

\section{De que clínica estamos falando}

E o que seria a prática clínica senão um catalisador de encontros produtores de saúde? Sabemos que a clínica moderna muitas vezes não funcionou com esse fim. Em prol da busca de verdades científicas, elegeu como seu objeto de estudo a doença, enquanto fato natural e objetivo, esquecendo o que realmente importava: as verdades que surgem a partir da experiência de "corpos agenciadores" no mundo. De acordo com Foucault (1977), era uma clínica estática e estéril (e em muitos casos ainda é), uma forma de dispor a verdade já adquirida e de apresentá-la a fim de que ela se desvelasse sistematicamente. Derivada de formas já constituídas de saber, não tinha capacidade de acarretar a invenção de um novo conjunto de discursos e práticas.

Defendemos aqui, tal como Machado, L. e Lavrador (2009), uma prática clínica enquanto desvio, processo de abertura às diferenças intensivas que pulsam em nós. Um lidar com a tensão entre as formas postas e as forças de um plano movente, uma desconstrução das figuras atuais e a possibilidade de construção de outros modos de exis- 
tência. Uma prática clínica capaz de expandir a vida, por estar onde a vida está, em seu território, cuidando para que não seja sobreposta por verdades transcendentes.

\section{Prática clínica no/de território}

Existem várias formas de entender a palavra território. Abordaremos algumas, no sentido de deixar mais clara a noção de território utilizada nesta pesquisa. $\mathrm{O}$ conceito de território é operado por várias disciplinas e parece irredutível a um único campo de saber, afinando-se com a proposta de uma clínica como abertura de passagens, que se realiza no "entre fronteiras". Há discussões sobre território nos campos da etologia, geografia, filosofia, psicologia, justiça e política.

Monken et al. (2008) realizam uma discussão interessante sobre a categoria "território" como referencial de análise no campo da saúde. Afirmam que na geografia existem duas grandes concepções do termo território. A primeira é a jurídico-política, provém da geografia política clássica e parece ser mais difundida entre as pessoas em geral. Aqui o termo território pode ser entendido como uma área demarcada pelas fronteiras nacionais de um Estado. A segunda compreensão parte da ideia de que a territorialidade dos homens é análoga à dos animais, e está na base da composição de territórios.

Existem críticas às duas concepções. Em relação à primeira, considera-se o perigo de atribuir exclusivamente ao Estado a constituição de territórios, sendo importante incorporar novos atores nesse processo. A chave do estudo do território é o poder, mas não só o exercido pelo Estado. Em relação à matriz etológica, existem perigos em estabelecer relações diretas entre comportamento animal e humano, tal como o de acreditar que os homens são predadores e dominadores de territórios devido às suas necessidades biológicas inatas.

Muito comumente na área da saúde a noção de território permanece associada à sua concepção jurídico-política. Como área político-administrativa, o território seria uma unidade geográfica sob a égide do planejamento e atuação de atores públicos, tais como trabalhadores e gestores das unidades do SUS. Seria um recorte do espaço, uma região geográfica e administrativa no âmbito de atuação de uma equipe de saúde, que a utilizaria para organizar seu trabalho.

Essa concepção de território, apesar de importante, é insuficiente quando pensamos na construção coletiva de práticas produtoras de saúde no contexto do SUS. Segundo Monken et al. (2008), noções mais atuais sobre o território consideram que este carrega sempre, de forma inseparável, uma dimensão simbólica, ou cultural em sentido estrito, e um aspecto material, de natureza predominantemente econômico-política. O geógrafo brasileiro Milton Santos (1998) contribuiu bastante para ampliação e discussão do conceito de território. Para o autor:

É o uso do território, e não o território em si mesmo, que faz dele objeto de análise social. Trata-se de uma forma impura, um híbrido, uma noção que, por isso mesmo, carece de constante revisão histórica. O que ele tem de permanente é ser nosso quadro de vida. Seu entendimento é, pois, fundamental para afastar o risco de alienação, o risco de perda de sentido da existência individual e coletiva (SANTOS, 1998, p. 15).

Neste sentido, no campo da saúde, o território pode ser entendido não só como o suporte da organização das práticas e serviços de saúde, mas também como território vivido, suporte de vida da população. Queremos destacar, como afirmam Macerata, Soares e Ramos (2014, p. 922), que um território se constitui como "vivo por ter uma dimensão não objetiva, não já formada, uma dimensão que é puro processo de expressão". Vamos nos deter agora sobre essa dimensão, a partir da definição de território existencial proposta por Deleuze e Guattari (1997) no livro Mil platôs: capitalismo e esquizofrenia, mais especificamente no "platô" intitulado "Acerca do ritornelo". Segundo os autores, o processo de constituição de um território existencial se faz por meio de um ritornelo. Este, por sua vez, pode ser entendido como ritmo, no sentido de repetição. Não se trata de uma repetição necessariamente cadenciada, mas uma repetição intrínseca ao próprio sistema, uma circularidade pura. Assim,

A cada círculo o que se repete é o próprio circular, ou seja, a cada círculo todo sistema é arrastado recriando-se, revelando assim uma diferença necessária. O ritornelo é então um conceito de constância, todavia uma constância que não se diz do mesmo. Sem ritornelo as partículas caóticas seguem rumos de tal forma desordenados que não é possível extrair do caos nenhuma forma, nenhum território (ARAÚJO, 2007, p. 116-117).

O ritornelo é composto de três momentos não sucessivos e evolutivos. Num desses momentos, no meio do caos, há um "esboço de um centro estável e calmo, estabilizador e calmante" (DELEUZE; GUATTARI, 1997, p. 116). Em outro, produzimos um "em-casa" não preexistente, que se faz através da organização de um espaço limitado, por meio de um círculo tracejado em volta do centro frágil e incerto. Tanto quanto se pode, as forças do caos ficam mantidas do lado de fora. Num outro momento, abrimos o círculo e permitimos a entrada de alguém ou então lançamo-nos para fora. Essa abertura se dá numa região criada pelo próprio círculo, não do lado onde se acumulam as antigas forças do caos. Rumo ao encontro de forças do futuro, arriscamo-nos numa improvisação.

Entendido dessa maneira, o território se faz em movimento, como um plano de consistência/imanência, composto por uma multiplicidade de dimensões, que se articula por linhas a outros planos. Essas ligações se fazem por meio de agenciamentos, já discutidos aqui. Trata-se da articulação de componentes heterogêneos que ganham consistência e produzem conexões de relações materiais com determinado regime de signos. Assim, um agenciamento produz território "quando alguns signos adquirem valor de propriedade e passam a demarcar esteticamente os limites de uma apropriação subjetiva" (LEMKE; SILVA, 2011, p. 996).

Em outras palavras, o território ganha consistência, de acordo com Guattari (1992, p. 42-43), por meio do "empréstimo de cadeias semióticas destacadas e desviadas de sua vocação significacional, ou de codificação. Aqui uma 
instância expressiva se funda sobre uma relação matéria-forma, que extrai formas complexas a partir de uma matéria caótica". Segundo Deleuze e Guattari (1997), o caos é constituído de vários meios, todos vibratórios. Os meios são como uma espécie de bloco de espaço-tempo composto pela repetição periódica de seus componentes. A resposta dos meios ao caos é o ritmo. Há território, portanto, quando há expressividade no ritmo, a partir do momento em que os componentes dos meios passam de funcionais para expressivos. Nesse sentido, num território, as funções não são primeiras, elas supõem antes uma expressividade que constitui o território.

Que efeitos esse modo de entender um território produz nas práticas clínicas? Contaremos com a ajuda de uma “experiência-questão" para potencializar essa discussão.

\section{Experiência-questão: caminhando e cantando e seguindo a canção}

Em 2015 a Oficina de Música era conduzida por um psicólogo-músico, que costuma tocar violão, e por mim. Talvez a palavra "conduzir" não seja a mais apropriada para descrever o que fazíamos. Considero que éramos abridores de portas, acompanhadores de fluxos, agenciadores de encontros que têm como intercessor a música.

Acontecia no CAPS Liberdade, em Aracaju, às quartas-feiras, e contava com a participação, em média, de 25 usuários. Costumávamos pesquisar as letras das músicas sugeridas pelos usuários na semana anterior por meio de nossos celulares e, enquanto eu as copiava no flip chart, o outro psicólogo ia aprendendo a tocá-las no violão. Não era raro que, mesmo vendo a porta fechada, um ou outro usuário batesse na porta e perguntasse: "Já vai começar?". Quando terminávamos de copiar as letras, íamos até o pátio e lançávamos o convite: “A Oficina de Música vai começar!". Alguns já estavam em pé, só esperando a porta se abrir, e ajudavam gritando ainda mais alto: "A Oficina de Música vai começar!". Outros estavam no pátio, ouvíamos o som das pedras de dominó sendo guardadas rapidamente. Já Ana ficava aguardando o chamado quase sempre sozinha, acocorada, encostada na parede da quadra que fica no fundo do CAPS. Por fim, existiam aqueles que na ocasião do chamado estavam dormindo e, por isso, precisam de um convite mais direcionado no pé do ouvido; uns levantavam quase que imediatamente, outros escolhiam continuar o cochilo. Com a sala cheia, perguntávamos como estavam, conversávamos um pouco e depois começávamos a cantar.

No dia 08/01/14, começamos a Oficina perguntando como tinham sido as festas de fim de ano, já que nesse período muitos não vieram ao CAPS. Adilson falou com muita raiva de como se sentia em relação a sua família: "Eles agem como se eu não existisse, outro dia minha mãe pediu para meu irmão me levar no CAPS. Ele respondeu que não era babá de doido, quebrei a moto dele e ele me enforcou. Meu irmão comprou uma caixa de som, só escuta música alta e minha irmã tem um filho recém-nascido que chora o tempo todo, quero dormir e não consigo." Alguém comentou: "Sei como é, pra gente é mais dificil dormir". Adilson continuou: "Fiquei depri- mido e tomei 15 comprimidos de carbamazepina". Sabia que o episódio da moto tinha acontecido já há algum tempo e que Adilson costumava ser agressivo com os familiares, principalmente quando bebia. Então, a intervenção aconteceu no intuito de também chamá-lo à responsabilidade: "Como fazer para essas coisas que ocorrem em sua família não o atingirem com tanta força? Já experimentou conversar com seus irmãos em vez de simplesmente exigir que eles mudem de comportamento?".

Eis que João, também muito afetado, falando o maior volume de palavras por Oficina na história de sua participação, defendeu Adilson:

Eu sei como é, minha família também não me entende, eles pensam que doença é só doença física. Não sou aposentado, eles não me dão dinheiro para eu comprar uma Coca... Outro dia ficaram sabendo que eu fui atrás de um rabo de saia, eu tenho minhas necessidades, né? Ai disseram que por causa disso eu já podia trabalhar. Eu fico calado, mas tenho vontade de esganar, eu não consigo trabalhar...

Carlos completou dizendo: "É por isso que odeio quando vocês ficam falando que a gente precisa passar menos tempo no CAPS, como se ficar em casa fosse bom". Reiteramos que além do CAPS e da própria casa existem vários outros lugares, mas naquele momento entendi que, antes de se tornar responsável por esse ou aquele comportamento, é importante sentir que existe. Como afirmar uma existência invisível, já que não segue à risca o padrão de normalidade de "trabalhar-ir atrás de um rabo de saia-casar-ter filhos"?

Parece que a conversa estava fazendo sentido para muitos, ninguém pediu para interrompê-la para começarmos a cantar. Quando iniciamos a cantoria, Adilson ainda estava sério, cabisbaixo, à medida que íamos cantando ia sendo contagiado. Ao final, cantou sozinho Página de amigos, de Chitãozinho e Chororó.

Até que ponto o que aparece de expressão às quartas-feiras, às duas horas, na sala verde do CAPS Liberdade é catalisado pela Oficina de Música, que funciona como espécie de ritornelo, ao fazer circular, de forma rítmica, componentes heterogêneos que passam a se articular, a se agenciar?

Começamos a questionar também se tomamos o território, em nossas práticas de atenção à saúde, a partir de seus sentidos e modos de expressão, ou de seus aspectos funcionais e utilitários. Fiquei surpresa quando Carlos afirmou, usando outras palavras, que o "território-casa" nem sempre pode ser entendido a partir de sua popular função de proteção, cuidado, pertencimento ou aconchego. Os personagens, as cenas de suas ações, vivenciadas em ambientes públicos ou privados, surgem através de expressões. Como nos falam Alvarez e Passos (2009, p. 134), "as condutas são efeitos dos signos expressivos característicos de dado território. [...] O território não se constitui como um domínio de ações e funções, mas sim como ethos, que é ao mesmo tempo morada e estilo".

Parece que Carlos, Adilson e João falavam da dificuldade de construir esse ethos, um "em-casa", na própria casa onde moravam. O que está em jogo aqui são 
os agenciamentos que configuram esta situação. Assim como não podemos tomar o território pelo domínio de uma função, não ganhamos muito o concebendo como o domínio de um sujeito. Com Macerata, Soares e Ramos (2014, p. 923), entendemos que, na prática clínica, os "sujeitos, os objetos e seus comportamentos deixam de ser o foco da intervenção. Se buscarmos deslocar o olhar de nossa intervenção, ao considerar os territórios existenciais, o que temos como foco são, antes dos sujeitos, paisagens subjetivas".

Os autores afirmam que essas paisagens são constituídas de diferentes fatores que identificamos e nomeamos objetivamente, tais como condições sociais, econômicas, sanitárias, culturais. No entanto, indissociável a essas formas objetivas, está uma dimensão processual. Nesse sentido, os territórios existenciais são expressividades que não são do domínio de seus agentes, que por sua vez costumam protagonizar o ato de expressar. Em vez disso, compõem-se na relação entre corpos e mundo.

Tomar a paisagem subjetiva como foco de nossas práticas, significa também nos colocarmos como coprodutor dessa paisagem. Trabalhador/pesquisador e usuários do SUS compõem e compartilham territórios existenciais e, numa relação de circularidade, codeterminam-se. Assim, por exemplo, a Oficina de Música e a prática da roda que ela instaura fazem circular a experiência "incluindo a todos e a tudo em um mesmo plano - plano sem hierarquias, embora com diferenças; sem homogeneidade, embora traçando um comum, uma comunicação" (ALVAREZ; PASSOS, 2009, p. 142). Quando Carlos falava que se sentia pressionado pelos trabalhadores do CAPS a passar menos tempo neste serviço e mais tempo em outros locais da cidade, ele estava mexendo num plano comum, do qual fazemos parte. Mas do que isso, Carlos estava denunciando a cidade onde mora, referindo dificuldade em ocupar seus espaços-tempo.

A cidade (seja Aracaju-SE, Contagem-MG, São Paulo-SP ou qualquer outra) é um entrecruzamento complexo de múltiplos territórios. De acordo com Sennett (1988), a cidade é um assentamento humano onde está dada a possibilidade de encontro com o estranho, entendido aqui no sentido de alteridade. Assim, o encontro com o outro que difere de mim (estranho) faz com que me torne diferente do que eu era. Esses encontros nem sempre são fáceis de acontecer na cidade, é o que Carlos nos diz. Aliás, não só Carlos, mas João também. Tem um lugar mais garantido na cidade quem segue à risca o padrão de normalidade de "trabalhar-ir-atrás-de-um-rabo-de-saia-casar-ter filhos".

Quando afirmamos a importância de uma prática clínica no território, estamos falando de compor um território existencial, engajando-se nele. Construir um fazer clínico indissociável de uma prática política. Trata-se de ocupar a cidade e seus espaços públicos para que, presentes nessa arena de lutas, onde há conflitos e diferentes jogos de força, possamos nos posicionar frente aos regimes de sociabilidade que estão postos.

Fractal, Rev. Psicol., v. 33 - n. 1, p. 31-40, 2021
Alex recebia o "bolsa-família", conseguiu uma carteirinha de passe-livre interestadual e, em algumas cidades onde passou, conseguiu dormir em albergues. Esses aspectos de sua vida nos permitem uma leitura da pólis, da cidade onde vive. A mudança na vida de qualquer um se faz colada com transformações em sua cidade, estado ou país. Tensionamos com mais vigor essa dupla transformação quando nossa prática clínica não fica reduzida apenas aos espaços dos nossos serviços, embora lindos territórios existenciais possam surgir das práticas que ocorrem nos CAPS, USF ou hospitais. As chances de (des)territorialização, expansão da vida e produção de saúde parecem ser ampliadas quando alargamos também as possibilidades de encontros. Às vezes, o que o usuário precisa não está no nosso serviço, mas em outro. E, às vezes, seu desejo não se conecta com ofertas de nenhum serviço, seja da saúde, da assistência, da educação, da previdência, etc. Cada vida se expande de vários jeitos, seja com coisas ou pessoas, na rua, com uma Coca, com uma carteirinha de passe, com profissionais da saúde, com vizinhos.

Como habitar territórios singulares, processuais e, portanto, imprevisíveis? É imprescindível sustentar um grau de desprendimento em relação às diretrizes de referência dominantes, tal como racionalidades estritamente técnicas e concepções que aprisionam subjetividades em formas identitárias. Desta forma, é preciso pôr teorias e práticas da área da saúde em novas bases, que contemplem uma estreita conexão com o território existencial dos usuários. Isso significa participar tanto da construção de territórios como de sua desconstrução. Lemke e Silva (2011) nos ajudam a entender esse processo ao lançarem mão de dois operadores conceituais - a integralidade e a desinstitucionalização.

De acordo com a Lei no 8.080 (BRASIL, 1990), a integralidade da assistência é entendida como conjunto articulado das ações e serviços preventivos e curativos, individuais e coletivos, demandados para cada caso em todos os níveis de complexidade do sistema. Um outro sentido comumente compartilhado para integralidade pode ser o de considerar, nas práticas de atenção à saúde, para além da dimensão física, a multiplicidade e processualidade de outros aspectos que constituem a vida: mental, social, cultural, político, espiritual, etc.

A exposição à complexidade do território contribui para a produção da integralidade do cuidado em ambos os sentidos, entendido tanto como a articulação de ações e serviços de atenção à saúde quanto como a afirmação e articulação de diversas dimensões que compõem a vida. Isso porque, segundo Lemke e Silva (2011, p. 994), esta exposição "territorializa o pensamento aos modos de vida dos usuários, contextualizando as práticas de cuidado”.

Com o operador conceitual da desinstitucionalização, visualizamos a importância também da desterritorialização de nossas práticas clínicas. $\mathrm{O}$ contexto de Reforma Psiquiátrica nos dá algumas pistas sobre o assunto. No Brasil, a instalação do dispositivo asilar e o surgimento da psiquiatria ocorreram no advento da República, sob o impacto da industrialização. O louco, que antes circulava 
de forma consentida nas ruas, passou a encarnar a figura da desordem urbana, requerendo um dispositivo de controle e segregação.

Assim, a transformação da loucura em doença e sua institucionalização foram possíveis graças à psiquiatria, que desenvolveu um aparato de práticas repressivas, tutelares, excludentes e iatrogênicas, pautadas no autoritarismo e na coerção. Diante dessa situação, ao longo dos anos várias tentativas de "Reformas Psiquiátricas" puderam ser experimentadas em vários países, destacando-se aqui o pensamento de Franco Basaglia, com o movimento da Psiquiatria Democrática Italiana, fundado em 1973.

Tal movimento, de crítica radical ao paradigma psiquiátrico, afirma a urgência da desinstitucionalização, ou seja, da desmontagem de saberes/práticas/discursos comprometidos com uma objetivação da loucura e sua redução à doença. Para tanto, aponta como necessário tanto a revisão das relações a partir das quais o saber médico funda sua práxis como a análise histórico-crítica a respeito da sociedade e da forma como esta se relaciona com o sofrimento e a diferença, como associa a loucura a qualidades morais de periculosidade e marginalidade, que acabam fortalecendo a correlação entre punição e terapêutica.

E o que isso tem a ver com território e desterritorialização? A criação de território é sempre criação de mundo. Esse mundo institucionalizado da loucura é habitado por muitos: pessoas com sofrimento mental, seus familiares, trabalhadores da área da saúde, indústrias farmacêuticas, políticos, etc. Foi forjado coletivamente e, do mesmo jeito que foi montado ao longo da história, pode ser desconstruído, desterritorializado, deixar de fazer sentido. Como indica Araújo (2007), a desterritorialização nos situa na passagem de um território a outro, localizando o caos não mais em um momento de constituição original, mas sim em um espaço entre-dois que convergirá para a criação de outros territórios.

Afirmamos, portanto, a importância de uma prática clínica no território, enquanto espaço-tempo vivo e mutante, onde têm lugar o conflito e sua negociação. Uma prática clínico-política, que tem condições de expandir vidas por estar engajada com o plano de sua constituição, plano coletivo, plano público. Numa prática no território é difícil se manter indiferente às condições de vida da população brasileira, às injustiças sociossanitárias. Por isso, ao afirmar uma clínica no território, estamos afirmando o próprio SUS, que surgiu num contexto de luta pela democratização das práticas de saúde. Estamos afirmando a desinstitucionalização não só no contexto da Reforma Psiquiátrica, mas de toda prática derivada do saber científico, ou de outro saber institucionalizante, que barre ou centralize o acesso à saúde. Afirmamos um cuidado sem centro, não-hospitalocêntrico, não-médico centrado. Um cuidado no território é espalhado, com vários protagonistas, em rede. A clínica no território é indissociável de uma clínica de território. Ou seja, a forma própria de a prática clínica se atualizar se faz por meio de sua condição de (des)construir territórios, de operar passagens. Araújo (2007, p. 21) nos ajuda a entender esse processo:
As passagens de um ponto a outro, sejam eles pontos da cidade, de um discurso ou de um corpo se movimentando num consultório, vão colocando lado a lado fragmentos, que vão formando paisagens e adquirindo sentidos. A clínica se revela então como a bricolagem de fragmentos que ora se conectam produzindo uma figura, ora se desconectam desestabilizando figuras já constituídas. Essa conexão/ desconexão se dá na medida em que percorremos os fragmentos rearrumando-os.

Por fim, a experimentação de uma prática clínica no/ de território produz mudanças no território da clínica, que vivencia uma porosidade de suas fronteiras. Assim, a clínica se faz em um movimento de modulação que confere transformação tanto em quem lhe demanda intervenção quanto no conjunto de técnicas, teorias e práticas que compõem a própria clínica.

\section{Considerações}

A partir da experiência relatada, sustentamos que pesquisa e intervenção são planos de um mesmo processo. Falamos de intervenção da pesquisa tanto no campo problemático de estudo - a prática clínica no contexto do SUS - como nos sujeitos que compõem essa prática - trabalhadores e usuários do SUS -, como também falamos de intervenção e transformação nas próprias pesquisadoras e na forma de produzir conhecimento.

Nesse sentido, ser psicóloga do CAPS e ao mesmo tempo escrever sobre práticas clínicas que lá ocorrem inevitavelmente produziu mudanças nas relações estabelecidas com colegas trabalhadores, estagiárias, usuários e gestores. Não raro compartilhava com estes as ressonâncias que as antenas cartográficas captavam nesse campo de práticas, solicitando ajuda na produção de sentido para signos soltos, sedentos de agenciamentos, o que por vezes nos ajudava a tomarmos, juntos, certas decisões.

Continuando, a experiência-questão "Jogando o corpo no mundo" nos fez pensar sobre os riscos de fundamentar práticas clínicas numa concepção de saúde enquanto essência que caracterizaria um estado de normalidade dos seres humanos. No encontro com Alex, habitando com ele suas (e nossas) paisagens subjetivas, percebemos a importância de afirmarmos a noção de saúde como um processo de produção, que nos convoca ao desafio de inventar formas de construir uma prática clínica de "corpos agenciadores" no contexto do SUS. Desafio porque os corpos são heterogêneos e mutantes, e as práticas que constituem o SUS também o são - ainda que a constante produção de uma subjetividade capitalística e sua interiorização através do Estado tente conter esse movimento ou estimulá-lo para que passe a funcionar de acordo com suas regras.

Diante do desafio, afirmamos ser possível construir práticas produtoras de saúde, quando estamos engajados com o plano de constituição da vida dos corpos que acompanhamos. Com a experiência-questão "Caminhando e cantando e seguindo a canção", as falas de Adilson e Carlos bradam pelo entendimento da noção de território a partir de seus sentidos e modos de expressão, que se dão num plano imanente e coletivo. É por estarmos imersos 
nesse plano que somos capazes de compor agenciamentos (im)possíveis e de conectar elementos dispersos. Daí a afirmação de uma clínica no/de território.

Não basta compartilhar territórios existenciais com os usuários que acompanhamos, ou propor tempos-espaços de convivência, coletivos. Os paradoxos existentes no exercício da prática clínica no SUS solicitam uma atitude. Trata-se de uma atitude de abertura, um convite a habitar e testar fronteiras. Uma "atitude-limite", segundo Martins (2009, p. 60), que liberta "da contingência que nos fez ser o que nós somos, a possibilidade de não mais ser, fazer ou pensar o que nós somos, fazemos e pensamos". É preciso desconfiar da "verdadeira vida" o tempo todo.

A partir da corporificação dessa atitude por parte de trabalhadores, gestores, usuários do SUS e seus familiares, podemos ver a circularidade se fazer, vislumbrar mudanças e construir novos caminhos para um SUS universal, integral e equânime. Habitamos e testamos fronteiras quando fazemos do SUS não uma ideologia fincada no campo da representação, mas uma política coletiva, pública, construída no cotidiano dos nossos serviços. Quando conseguimos nos reposicionar, a cada encontro, com aquilo que é diferente de nós, cuidando assim de nossas relações. Quando somos capazes de transversalizar saberes, desnaturalizar especialismos, gerar, enfim, um plano comum na clínica, uma clínica de/no território de "corpos agenciadores".

\section{Informações sobre as autoras:}

\section{Mariane Marques Santos Amaral}

(iD) https://orcid.org/0000-0001-8099-5252

\section{(9) http://lattes.cnpq.br/7952286112974559}

Possui graduação em Psicologia pela Universidade Federal de Sergipe (2006). Especialista em Saúde Mental pelo Programa de Residência Multiprofissional em Saúde da Universidade do Estado da Bahia. Mestre em Psicologia Social pela Universidade Federal de Sergipe (2015). Especialista em Psicologia Analítica pela Profint (2020). Foi professora substituta do Departamento de Psicologia da Universidade Federal de Sergipe (2009) e trabalhou como apoiadora institucional tanto na Rede Cegonha/Ministério da Saúde (2011-2013) como na Rede de Atenção Psicossocial de Aracaju (2015-2017 e 2018-2019). Tem experiência na área da Psicologia Social e Institucional, atuando principalmente nos campos da saúde coletiva, saúde mental e saúde materno-infantil. Atualmente realiza Acompanhamento Terapêutico (AT) e psicoterapia individual, além de trabalhar no SUS como psicóloga no Centro de Atenção Psicossocial Liberdade em Aracaju-SE (desde 2009).

\section{Liliana da Escóssia}

\section{iD https://orcid.org/0000-0001-6483-394X \\ (9) http://lattes.cnpq.br/0338485193024260}

Possui Doutorado em Psicologia pela Universidade Federal do Rio de Janeiro (2003), Doutorado Sanduíche pelo Centre de Recherche en Epistemologie Apliqué - Ecole Polytechnique de Paris (2002). Mestrado em Psicologia pela Pontifícia Universidade Católica de São Paulo (1997). Entre 2009 e 2010 realizou pós-doutorado na Universidade Federal Fluminense. Aposentou-se como professora titular da Universidade Federal de Sergipe, em 2019. Atua e realiza pesquisas no campo da Psicologia Social e Institucional, Saúde Coletiva e Saúde Mental, com ênfase nos seguintes temas: saúde e produção de subjetividade; tecnologias e modos de subjetivação/ individuação; produção de coletivos e territórios em saúde, políticas e práticas de redução de danos, cuidado na rua, humanização e práticas coletivas em saúde.

\section{Contribuição das autoras:}

As autoras colaboraram ao longo do processo, desde a elaboração até a revisão final do manuscrito. Ambas aprovaram o manuscrito final para publicação.

\section{Como citar este artigo:}

\section{ABNT}

AMARAL, Mariane Marques Santos; ESCÓSSIA, Liliana da. Por uma clínica de(s) território no contexto do SUS. Fractal: Revista de Psicologia, Niterói, v. 33, n. 1, p. 31-40, jan./abr. 2021. https:// doi.org/10.22409/1984-0292/v33i1/5782

\section{APA}

Amaral, M. M. S., \& Escóssia, L. (2021, Janeiro/Abril). Por uma clínica de(s) território no contexto do SUS. Fractal: Revista de Psicologia, 33(1), 31-40. doi: https://doi.org/10.22409/1984-0292/ v33i1/5782

\section{Copyright:}

Copyright (C) 2021 Amaral, M. M. S., \& Escóssia, L. Este é um artigo em acesso aberto distribuído nos termos da Licença Creative Commons Atribuição que permite o uso irrestrito, a distribuição e reprodução em qualquer meio desde que o artigo original seja devidamente citado.

Copyright (C) 2021 Amaral, M. M. S., \& Escóssia, L. This is an Open Access article distributed under the terms of the Creative Commons Attribution License, which permits unrestricted use, distribution, and reproduction in any medium, provided the original article is properly cited.

\section{Referências}

ALEXANDRE, Marta de Lima; ROMAGNOLI, Roberta Carvalho. Prática do Psicólogo na Atenção Básica - SUS: conexões com a clínica no território. Contextos Clínicos, São Leopoldo, v. 10, n. 2, p. 284-299, jul./dez. 2017. http://dx.doi. org/10.4013/ctc.2017.102.12

ALVAREZ, Johnny; PASSOS, Eduardo. Cartografar é habitar um território existencial. In: PASSOS, Eduardo; KASTRUP, Virgínia; ESCÓSSIA, Liliana da (Org.). Pistas do método da cartografia: pesquisa-intervenção e produção de subjetividade. Porto Alegre: Sulina, 2009. p. 131-149.

ARAÚJO, Fábio. Um passeio esquizo pelo acompanhamento terapêutico: dos especialismos à política da amizade. Niterói: Edição do autor, 2007.

BRASIL. Presidência da República. Casa Civil. Subchefia para Assuntos Jurídicos. Lei $n^{\circ} 8.080$, de 19 de setembro de 1990. Dispõe sobre as condições para a promoção, proteção e recuperação da saúde, a organização e o funcionamento dos serviços correspondentes e dá outras providências. Brasília, 1990. Disponível em: http://www.planalto.gov.br/ccivil 03/ leis/18080.htm. Acesso em: 22 ago. 2017.

BRASIL. Ministério da Saúde. Secretaria de Atenção à Saúde. Política Nacional de Humanização da Atenção e Gestão do SUS. Clínica ampliada e compartilhada. Brasília: MS, 2009. Disponível em: http://bvsms.saude.gov.br/bvs/publicacoes/ clinica_ampliada_compartilhada.pdf. Acesso em: 26 jan. 2018.

CANGUILHEM, Georges. O normal e o patológico. Rio de Janeiro: Forense Universitária, 1978.

DELEUZE, Gilles; GUATTARI, Félix. Mil platôs: capitalismo e esquizofrenia. Rio de Janeiro: Editora 34, 1997. v. 4. 
DELEUZE, Gilles; PARNET, Claire. Diálogos. São Paulo: Escuta, 1998.

DESCARTES, René. Discurso do método. São Paulo: Martins Fontes, 1996.

ESCÓSSIA, Liliana da. $O$ coletivo como plano de coengendramento do indivíduo e da sociedade. Aracaju: EDUFS, 2014.

FOUCAULT, Michel. O nascimento da clínica. Rio de Janeiro: Forense Universitária, 1977.

FOUCAULT, Michel. Microfísica do poder. 16. ed. Tradução de Roberto Machado. Rio de Janeiro: Graal, 2001.

FOUCAULT, Michel. Conversa com Michel Foucault (Entrevista com D. Trombadori). In: MOTTA, Manoel Barros da (Org.). Repensar a política: Rio de Janeiro: Forense Universitária, 2010. Coleção Ditos \& Escritos, v. 6, p. 289-347.

FOUCAULT, Michel. A coragem da verdade: o governo de si e dos outros II. Curso no Collège de France (1983-1984). São Paulo: Martins Fontes, 2011.

FUGANTI, Luiz. Saúde, desejo e pensamento. São Paulo: Linha de Fuga, 2008.

GUATTARI, Félix. Caosmose: um novo paradigma estético. São Paulo: Editora 34, 1992.

IGNÁCIO, Paula Sales. Caminhos para a avaliação: a construção de uma proposta de avaliação de dispositivos que favorecem a diretriz de clínica ampliada da Política Nacional de Humanização na Atenção Básica. 2011. 168 f. Dissertação (Mestrado em Saúde Pública)-Programa de Pós-Graduação em Saúde Pública, Escola Nacional de Saúde Pública, Fiocruz, Rio de Janeiro, 2011.

KASTRUP, Virginia. O método da cartografia e os quatro níveis de intervenção. In: CASTRO, Lúcia Rabello de; BESSET, Vera Lopes (Org.). Pesquisa-intervenção na infância e juventude. Rio de Janeiro: Nau, 2008. p. 465-481.

LEMKE, Ruben Artur; SILVA, Rosane Azevedo Neves da. Um estudo sobre a itinerância como estratégia de cuidado no contexto das políticas públicas de saúde no Brasil. Physis, Rio de Janeiro, v. 21, n. 3, p. 979-1004, jul./set. 2011. https:/doi. org/10.1590/S0103-73312011000300012

LIMA, Elizabeth Maria F. de Araújo; YASUI, Silvio. Territórios e sentidos: espaço, cultura, subjetividade e cuidado na atenção psicossocial. Saúde em debate, Rio de Janeiro, v. 38, n. 102, p. 593-606, set. 2014. http://dx.doi.org/10.5935/01031104.20140055

MACERATA, Iacã; SOARES, José Guilherme Neves; RAMOS, Julia Florêncio Carvalho. Apoio como cuidado de territórios existenciais: atenção básica e a rua. Interface: Comunicação, Saúde, Educação, Botucatu, v. 18, supl. 1, p. 919-930, 2014. https://doi.org/10.1590/1807-57622013.0210

MACHADO, Dagoberto de Oliveira. Movimentos na educação física: por uma ética dos corpos. 2011. 113 f. Dissertação (Mestrado)-Programa de Pós-graduação em Educação, Universidade Federal do Rio Grande do Sul, Porto Alegre, 2011.

MACHADO, Dagoberto de Oliveira; VASCONCELOS, Michele de Freitas F. de; MELO, Aldo Rezende de. O corpo como fio condutor para ampliação da clínica. Revista Polis e Psique, v. 2, n. 3, p.147-170, 2012. https://doi. org/10.22456/2238-152X.40325
MACHADO, Leila Domingues; LAVRADOR, Maria Cristina Campello. Por uma clínica da expansão da vida. Interface: Comunicação, Saúde, Educação, Botucatu, v. 13, supl.1, p. 515521, 2009. https://doi.org/10.1590/S1414-32832009000500004

MARTINS, Carlos José. Figurações de uma atitude filosófica não fascista. In: RAGO, Margareth; VEIGA-NETO, Alfredo (Orgs.). Para uma vida não fascista. Belo Horizonte: Autêntica, 2009. p. 51-62.

MONKEN, Mauricio et al. O território na saúde: construindo referências para análises em saúde e ambiente. In: MIRANDA, Ary Carvalho de et al. (Org.). Território, ambiente e saúde. Rio de Janeiro: Fiocruz, 2008. p. 23-42.

NIETZSCHE, Friedrich W. Vontade de poder. Tradução de Marcos Sinésio Pereira Fernandes e Francisco José Dias de Moraes. Rio de Janeiro: Contraponto, 2008.

PASSOS, Eduardo; BARROS, Regina Benevides de. A cartografia como método de pesquisa-intervenção. In: PASSOS, Eduardo; KASTRUP, Virginia; ESCÓSSIA, Liliana da (Org). Pistas do método da cartografia: pesquisa-intervenção e produção de subjetividade. Porto Alegre: Sulina, 2009. p. 1731.

SANTOS, Milton. O retorno do território. In: SANTOS, Milton; SOUZA, Maria Adélia de; SILVEIRA, Maria Laura (Org.). Território: globalização e fragmentação. 4 ed. São Paulo: Hucitec/ANP, 1998. p. 15-20.

SENNETT, Richard. O declínio do homem público. São Paulo: Cia das Letras, 1988.

VEYNE, Paul M. Como se escreve a história: Foucault revoluciona a história. Brasília: UNB, 1982. 